a 19-kyr meltwater pulse originating in the Northern Hemisphere contributed to early deglacial warming in the Southern Hemisphere, while maintaining a cold Northern Hemisphere through its effect on the Atlantic THC and ocean heat transport (Clark et al., 2004).

A similar temporal shape to the B/A onset (Fig. 1a) is detected at other abrupt stadial (cold) to interstadial (warm) transitions, named Dansgaard-Oeschger (DO) events, during the last glacial period (Dansgaard et al., 1984). These millennial-time scale variations have been linked to various mechanisms such as a salt oscillator (Broecker et al., 1990), deep-decoupling oscillations (Winton, 1993; Schulz et al., 2002), latitudinal shifts in convection sites associated with THC changes induced by freshwater flux perturbations in the North Atlantic (Ganopolski and Rahmstorf, 2001), and a stochastic resonance phenomenon (Ganopolski and Rahmstorf, 2002; Rahmstorf and Alley, 2002). The trigger of these millennial-time scale variations is unknown and there is debate as to whether these fluctuations are regular or stochastic (Wunsch, 2000; Schulz, 2002; Rahmstorf, 2003). Here we argue that our mechanism for the B/A transition might be similar to other DO events during the glacial phase. However, the warm and cold water routes of the oceanic conveyor belt only temporarily gained in strength, and returned to the glacial mode with reduced strength of the ACC and a relatively northward circumAntarctic frontal system compared to its present day position. In contrast, the southward migration of these fronts prior to the B/A transition is accompanied by deglacial warming, which activates the "flywheel" of the oceanic conveyor belt (Fig. 1, 2). Like the "conveyor belt" metaphor (Broecker, 1991; Brüning and Lohmann, 1999) the flywheel metaphor illuminates a basic idea. In our case the Southern Ocean can be understood as the engine for the oceanic transport system on glacialinterglacial time scales.

Our study suggests that the Achilles Heel (Broecker, 1991) and the flywheel of the Atlantic overturning circulation on paleoclimate timescales are located in the North Atlantic and the Southern Ocean, respectively (Fig. 2). A zone of special interest is the area around the Cape of Good Hope because it represents an import route of relatively warm and saline water from the Indian Ocean (Fig. 2c) that is thought to precondition NADW formation (Gordon et al., 1992). Berger and Wefer (1996) surmise that this narrow portal is directly related to the position of the sup-tropical convergence zone. Therefore, a northward displacement of this front could reduce (Gersonde et al.,
2003; Paul and Schäfer-Neth, 2003) or even pinch off access, leading to speculation that the reopening of the Agulhas gap at the end of the last ice age may have played a role in restarting the Atlantic THC (Berger and Wefer, 1996). Since the South Atlantic is characterized by a number of unique dynamical features, such as the large Agulhas Rings (Schouten et al., 2002) that form a key link in the THC, it is of interest to investigate the flywheel and its respective energy source, using high-resolution models of the South Atlantic, to obtain a more detailed view of this region.

\section{REFERENCES}

Berger, W. H. and Wefer, G., 1996: Expeditions in to the past: Paleoceanographic studies in the South Atlantic. In: The South Atlantic: Present and Past Circulation; Wefer G., Berger WH, Siedler G, Webb D. J. (eds.), Springer-Verlag, 363-410.

Blunier, T. and Brook, E. J., 2001: Timing of millennial-scale climate change in Antarctica and Greenland during the last glacial period. Science, 291, 109-112

Knorr, G. and Lohmann, G., (2003): Southern Ocean origin for the resumption of Atlantic thermohaline circulation during deglaciation. Nature, 424, 532-536.

Lohmann, G. and Schulz, M., (2000): Reconciling Bølling warmth with peak deglacial meltwater discharge. Paleoceanography, 15, 537-540.

Stocker, T. F., (2003): Global change: South dials north. Nature, 424, 496-499 doi:10.1038/424496a.

For full references please see:

www.pages-igbp.org/products/newsletters/ref2004_1.html

\title{
Sharp Cooling of the Northern Hemisphere in the Early Subatlantic Age (650 - 280 BC)
}

\author{
V. V. KLImenko \\ Global Energy Problems Laboratory, Moscow Energy Institute,14 Krasnokazarmennaya St., Moscow, 111250, Russia; gepl@deans.mpei.ac.ru
}

About 2,500 years ago, a strong cooling happened on the Earth. The evidence for this is found not only in numerous climatic indicators (glacier and tree-line position in the mountains, tree ring thickness, fossil pollen spectra, isotopic composition of ice, lacustrine and marine deposits) but in social history as well. Papers by many ancient authors (Herodotus, Livy Andronicus, Eratosthenes), as well as Chinese and Babylonian chronicles, describe a climatic pattern that differs greatly from the present, not only in temperature but also in humidity. They come from that period when the Scandinavian legend of Ragnarök originated (the doom of the gods and the entire world). Presumably, it implies that there was a critical change in the common natural environment. It is not surprising that it was this cooling that was chosen in paleoclimatology as a universal chronological boundary separating the penultimate (Subboreal) from the present (Subatlantic) epoch. However, there are still no satisfactory answers to the following fundamental questions:

- Was the Subatlantic coolingglobal?

- When and at what level was the maximum cooling attained?

-What was the distribution pattern of temperature and precipitation during this period?

A few highlights of my study, which addresses these questions, are presented here. Detailed information is given elsewhere (Klimenko, 2004). 


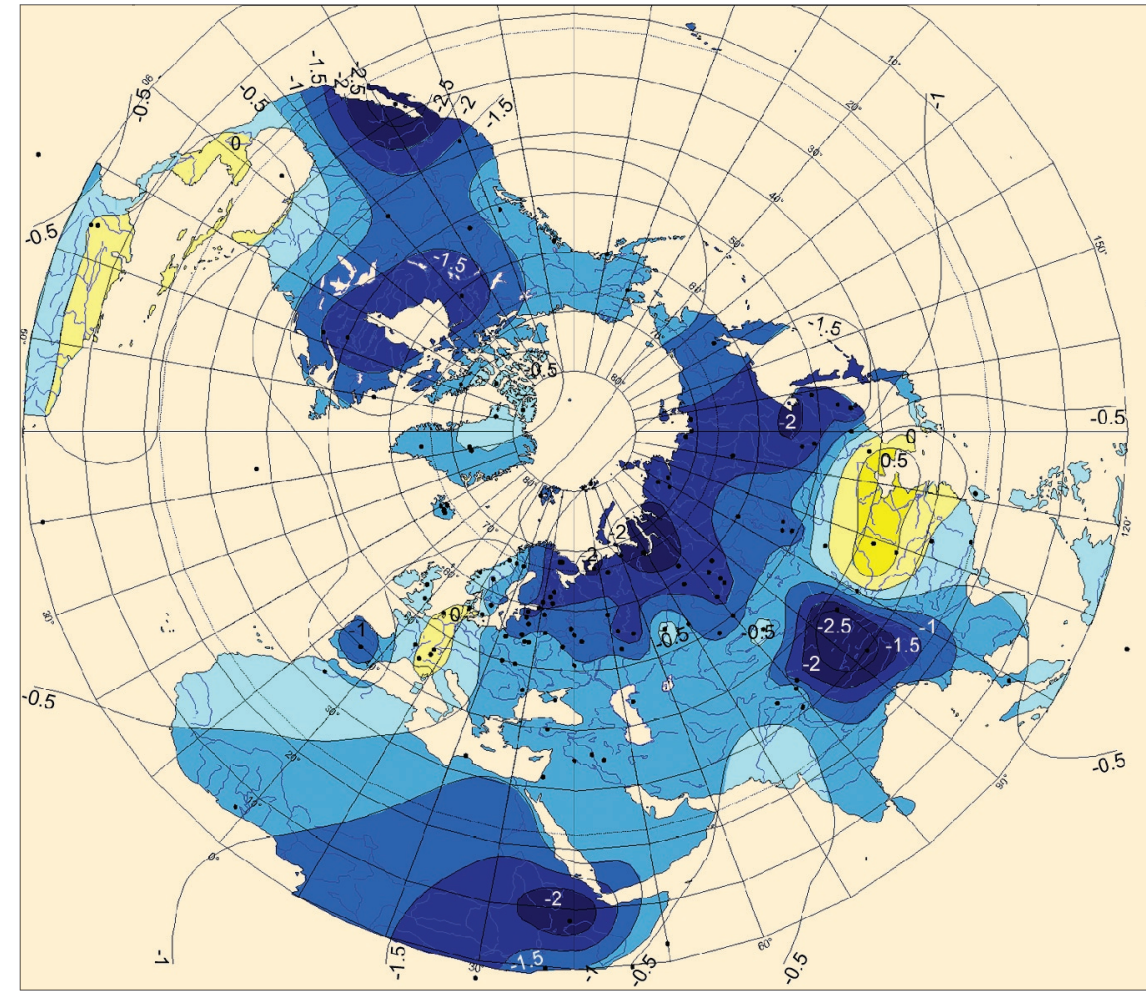

Fig. 1: Mean annual temperatures $\left({ }^{\circ} \mathrm{C}\right)$ during the maximum cooling of the Early Subatlantic Epoch compared to present values. Dots represent the locations of paleoreconstruction sites (Klimenko, 2004).

There are grounds to believe that the cooling of the Early Subatlantic Age (ESA), along with the Little Ice Age (LIA), was one of the strongest throughout the Late Holocene and, hence, marks the lower boundary of the natural climatic change at a millennial timescale. Not only climatology is actively interested in studying the ESA cooling, since its chronological boundaries roughly correspond to what Karl Jaspers referred to as the 'axial age' of history, i.e. the epoch of a remarkable, unique outburst of human intellectual and spiritual life that left clear historical evidence in different parts of the world. That such a coincidence is not accidental is confirmed by historical/climatological comparative studies (Klimenko 1998).

Even though the fact that a sharp cooling occurred during the ESA does not itself seem to be questioned, there are appreciable discrepancies concerning the chronological boundaries of this event. The majority of the data fall within the range of 2500-2200 radiocarbon yr BP, or 650-280 B.C. according to modern calibration (Stuiver et al., 1998). A thorough study of the most precisely dated experimental material enables the B.C.
ESA event to be characterised as an by a short-term warr between ca. 450 and 380 ent, culminating at 280
In order to compile maps of the main climatic parameter anomalies, I used the whole set of available paleoclimatic data, which involved reconstructions based on palynological data, glacier oscillations, and lake level fluctuations, as well as isotopic, dendrochronological, and historical data. In addition to our own data, I used literature data from 330 independent sources comprising information about the ESA climate in 579 sites of the Northern Hemisphere, 192 sites having quantitative reconstructions. The deviation of the annual mean temperature from present-day values (1901-1960 average) shows considerable spatial irregularity (Fig 1), the maximum negative anomalies being observed not only in high latitudes (on the continental periphery of the Barents and Kara Seas) but also on the Tibetan and Ethiopian Highlands. Nevertheless, against this background of dominant negative anomalies, there are areas where the annual mean temperature was higher than at present (e.g. Central America or China).

For the Northern Hemisphere, I assess the annual temperature anomaly during the ESA maximum cooling to be between -0.5

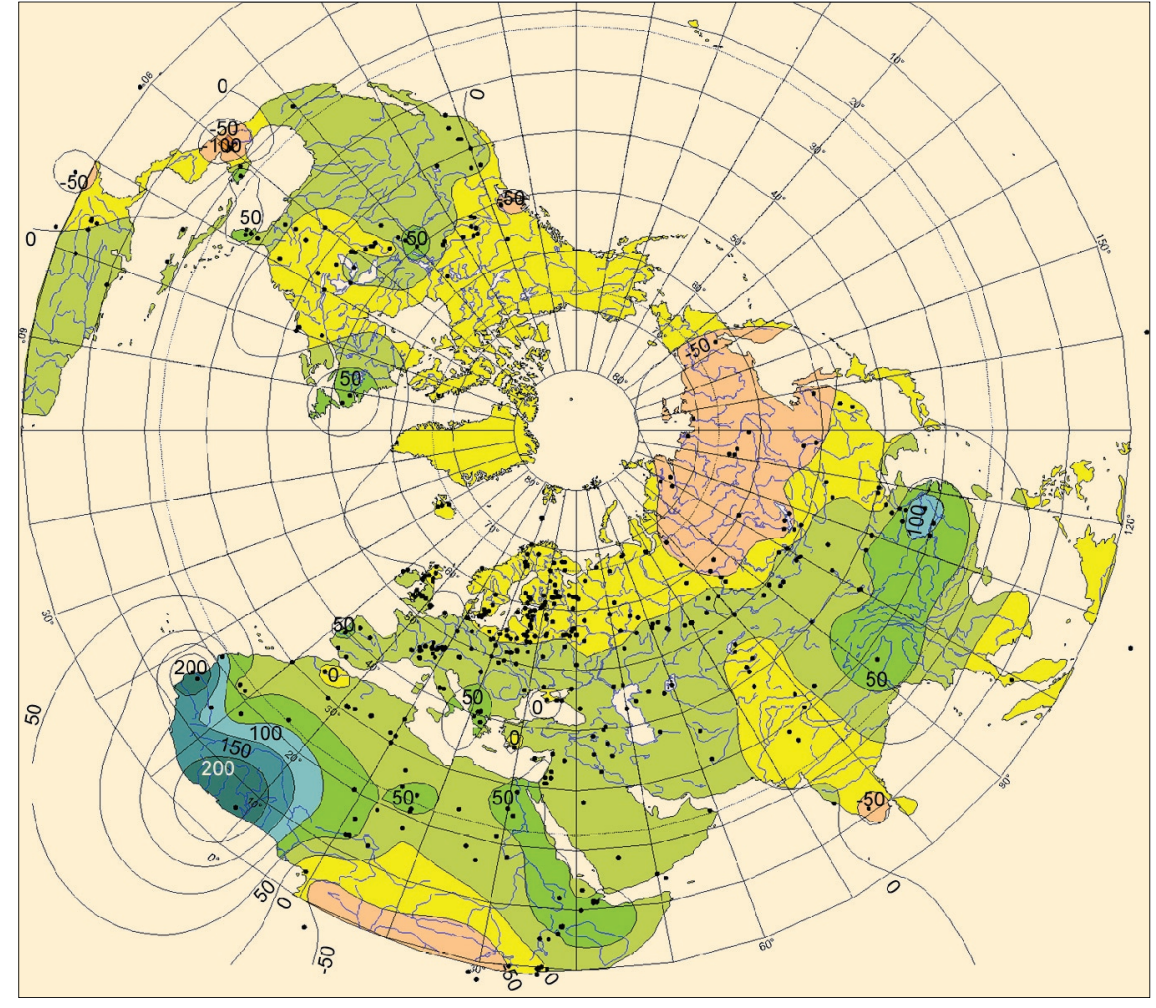

Fig. 2: Mean annual precipitation rate ( $\mathrm{mm} / \mathrm{year}$ ) during the maximum cooling of the Early Subatlantic Epoch compared to present values (Klimenko, 2004) 
and $-0.6^{\circ} \mathrm{C}$, when compared to the 1901-1960 reference period. This is substantially lower than the anomaly of $-0.23^{\circ} \mathrm{C}$ for the coldest decade of 1901-1910 in the period of modern instrumental observations and, I think, matches the values of the coldest Little Ice Age decades (e.g. 1450's or 1690's).

In paleoclimatology, the ESA period is generally considered to have been cold and humid. Indeed, positive anomalies of annual mean precipitation prevailed in most of the Northern Hemisphere and occasionally reached substantial values, in excess of 150-200 mm/ $\mathrm{yr}$, in western Africa and eastern China (Fig. 2). The whole Sahara was considerably more humid than now and there is historical evidence that men could easily cross what is now the world's greatest desert (Hennig, 1944). At the same time, only negative precipitation anomalies were observed in high latitudes on all the continents. Another vast drier zone spanned tropical areas of Asia, Africa, and Central and South America.

According to my estimates, the precipitation anomaly, averaged over the Northern Hemisphere, was $14 \mathrm{~mm} / \mathrm{yr}$ or ca. $1.5 \%$ higher than the present-day value. Hence, the ESA cold epoch was actually humid. This indicates that the relationship between zonal and hemispheric temperature and humidity is not merely nonlinear, which is well known, but nonmonotonous, i.e. humidity might increase with slight cooling. This is probably related to the fact that some decrease in the moisture content of the atmosphere is completely compensated by stronger westerlies in temperate and subtropical latitudes.

\footnotetext{
REFERENCES

Klimenko, V. V., 2004: Cold Climate of the Early Subatlantic Epoch in the Northern Hemisphere. MEI Publ., Moscow, 144 pp.

Klimenko, V. V., 1998: Climate and Human History during the Epoch of First High Cultures (3500-500 B. C). Vostok (Oriens). No. 4, 5-24.

Stuiver, M., Reimer P. J., Bard E., Beck J. W., Burr G. S., Hughen K. A., Kromer B., McCormac J., Van der Plicht J. and Spurk M., 1998: INTCAL 98 radiocarbon age calibration $24,000-0$ cal BP. Radiocarbon. 40 (3), 1041-1083

Hennig, R., 1944: Terrae Incognitae. Band I. Leiden.
}

\section{The Behavior of Modern Low-Latitude Glaciers}

Georg Kaser ${ }^{1}$, Christian Georges ${ }^{1}$, Irmgard Juen ${ }^{1}$, Thomas Mölg ${ }^{1}$, Patrick Wagnon ${ }^{2}$ and Bernard Francou ${ }^{2}$

${ }^{1}$ Tropical Glaciology Group, Institute of Geography, Innsbruck University, Austria; georg.kaser@uibk.ac.at, christian.georges@uibk.ac.at, irmgard.juen@uibk.ac.at, thomas.moelg@uibk.ac.at

${ }^{2}$ RDD-LGGE, BP 9638402 St Martin d'Heres Cedex, France; patrick.wagnon@glaciog.ujf-grenoble.fr, bernard.francou@lgge.obs.ujf-grenoble.fr

Around 1990, glaciers on lowlatitude high mountains - in the South American Andes between Venezuela and Northern Chile, on the East African mountains Kenya, Rwenzori and Kilimanjaro, and on Irian Jaya (New Guinea)-covered an area somewhat less than 2,500 $\mathrm{km}^{2}$. More than $99 \%$ of this area was in the Andes (Kaser, 1999; Kaser and Osmaston, 2002). These glaciers have all, following the global trend, retreated from their Little Ice Age extent after 1850 (Table 1) (Hastenrath, 2001). Secondary to the general retreat, and embedded in the global trend again, advances were observed around 1900, in the 1920's and in the 1970's (Kaser, 1999; Hastenrath, 2001). In the Cordillera Blanca, as most probably throughout the Peruvian Cordilleras (Albert, 2004), a more or less continuous snow cover on most of the glacier surfaces from October 1998 until May 2002 led to an interruption in the general retreat and even to tongue advances of some glaciers. Still, detailed information is scarce and the overall picture is all but complete. Nevertheless, the general retreat was strong and

Table 1: Modern retreat of low-latitude glaciers (after Kaser, 1999); (1) Thompson et al., 2002, (2) Georges, 2004.

\begin{tabular}{|l|ll|ll|}
\hline \multicolumn{1}{c}{} & \multicolumn{4}{c|}{ Year: glacier surface area $\left(\mathrm{km}^{2}\right)$} \\
\cline { 2 - 5 } Irian Jaya & $1850:$ & 19.3 & $1990:$ & 3.0 \\
Mount Kenya & $1899:$ & 1.6 & $1993:$ & 0.4 \\
Kilimanjaro & $1850:$ & 20.0 & $2000:$ & $2.6(1)$ \\
Central Rwenzori & $1906:$ & 6.5 & $1990:$ & 1.7 \\
Cordillera Real & $1920:$ & 28.6 & $1975:$ & 25 \\
Cordillera Blanca & $1850:$ & 870 & $2000:$ & 600 (2) \\
\hline
\end{tabular}

in some areas glaciers have vanished or are close to disappearing (Ramírez et al., 2001; Thompson et al., 2002). Glacier remnants on Irian Jaya (New Guinea) are about to disappear, as revealed by recent IKONOS satellite images from June 2002, showing that there are only two small glaciers left (Klein, pers. comm.).

The impact of climate on lowlatitude glaciers can be described with common glaciological laws but-because of the particular climate in the tropics and subtropics-various parameterizations have to be re-evaluated from several simplifications successfully applied to mid- and high-latitude glacier studies. If mechanical processes like avalanches and calving are excluded, the mass balance of a glacier is composed of accumulation of solid precipitation and ablation due to melting and sublimation. All these processes are related to solar radiation at the top of the atmosphere, air temperature, and atmospheric moisture content, only the first being entirely independent from the others. The atmospheric moisture content influences atmospheric emissivity and determines cloudiness, precipitation, and air humidity.

Relations between glacier mass balance and atmospheric moisture content are complex. The crucial role of sublimation from the glacier surface is noteworthy. Sublimation is driven by the vapor pressure gradient between the glacier surface and the overlying atmosphere. In contrast, melting has no driving 